\title{
The platelet defect in acute myeloid leukaemia
}

\author{
BE WOODCOCK, PC COOPER, PR BROWN, C PICKERING, DA WINFIELD, \\ FE PRESTON
}

From the University Department of Haematology, Royal Hallamshire Hospital, Sheffield S10 2JF

SUMMARY In a study of platelets from 13 patients with acute myeloid leukaemia abnormal aggregation and release reactions were found. A previously unrecognised quantitative defect of thromboxane $\mathrm{B}_{2}$ production may, at least in part, explain these findings. In contrast to a previous report, we were unable to show a convincing storage pool defect in these platelets. The platelet membrane glycoproteins were largely normal.

Acute myeloblastic leukaemia is a malignant disorder in which haemorrhage is frequent and life threatening. Although haemorrhage is usually associated with thrombocytopenia, a thrombocytopathy is believed to contribute. ${ }^{1}$ We have extended previous observations of this abnormality. We have confined ourselves to platelets from patients with acute myeloblastic leukaemia to avoid the problems of interpretation inherent when heterogenous conditions are combined under the general term "acute leukaemia," as has been done previously.

\section{Patients and methods}

\section{PATIENTS}

The 13 patients studied were diagnosed and their disease classified according to the FAB criteria ${ }^{2}$ by agreement between at least two observers. These patients were selected when their peripheral blood platelet counts were sufficient to yield a platelet rich plasma count of $100 \times 10^{9} / 1$ or greater and by the absence of systemic infection or major haemorrhage. At the time of study there was no clinical or laboratory evidence of disseminated intravascular coagulation. The latter was excluded by determination of the plasma fibrinogen, thrombin time, prothrombin time, kaolin cephalin clotting time, and the fibrin degradation products. All patients were studied before chemotherapy and no patient had received drugs known to affect platelet function for one week before study. Normal healthy hospital

Accepted for publication 5 September 1984

This work was presented to the IXth International Congress on Thrombosis and Haemostasis in Stockholm in July 1983 and appears in abstract form in Thrombosis and Haemostasis (Stuttgart) 1983;50:360. staff were used as controls.

The skin bleeding time was measured by the template method.

Blood sampling was performed via a $21 \mathrm{G}$ needle with clean venepuncture and minimal venous stasis. Blood was anticoagulated with $3.8 \%$ trisodium citrate at a ratio of 9:1. Platelet rich plasma was prepared by centrifugation at $150 \mathrm{~g}$ for $5 \mathrm{~min}$ and platelet poor plasma by centrifugation at $1800 \mathrm{~g}$ for $15 \mathrm{~min}$. The platelet rich plasma count was adjusted to $300 \times 10^{9} / 1$ where possible and was always greater than $100 \times 10^{\%} / 1$. Platelets from normal subjects were studied at concentrations of $100 \times 10^{9} / 1$ and $300 \times 10^{9} / 1$.

PLATELET AGGREGATION AND THROMBOXANE PRODUCTION

Platelet aggregation was performed in a dual channel instrument (Payton) by the method of Born. The maximum change in light transmission was recorded and expressed as a percentage of the difference between that obtained with platelet rich plasma and that with platelet poor plasma. The final concentrations of aggregating agents were: adenosine diphosphate (ADP), $1 \mu \mathrm{mol} / \mathrm{l}, 5 \mu \mathrm{mol} / \mathrm{l}$; and collagen, 2 $\mu \mathrm{g} / \mathrm{ml}$ and $4 \mu \mathrm{g} / \mathrm{ml}$ (Horm Chemie). Thromboxane $\mathrm{B}_{2}$ was measured by radioimmunoassay after aggregation of platelet rich plasma with $4 \mu \mathrm{g} / \mathrm{ml} \mathrm{col-}$ lagen for $5 \mathrm{~min}^{3}$

5-HYDROXYTRYPTAMINE UPTAKE AND RELEASE 5-hydroxytryptamine uptake and release were measured using ${ }^{14} \mathrm{C}$ labelled 5-hydroxytryptamine at a final concentration of $0.01 \mathrm{mmol} / 1$ (Radiochemicals, Amersham; specific activity $56 \mathrm{mCi} / \mathrm{mM}$ ). Four and a half millilitres of platelet rich plasma was incubated at $37^{\circ} \mathrm{C}$ with $0.5 \mathrm{ml}{ }^{14} \mathrm{C}$-5-hydroxytryptamine for $30 \mathrm{~min}$ (proportionate reduction was 
made for platelet rich plasma counts of less than $\mathbf{3 0 0}$ $\times 10^{9} / \mathrm{l}$ ). Then $0.2 \mathrm{ml}$ of platelet rich plasma and 20 $\mu \mathrm{l}$ of $2 \mathrm{M}$ edetic acid were spun in an Eppendorf centrifuge and $0.1 \mathrm{ml}$ of supernatant was removed for counting. The uptake is the difference in counts, expressed as a percentage of the preincubation count. Next $0.3 \mathrm{ml}$ of labelled platelet rich plasma was aggregated with $30 \mu \mathrm{l}$ of collagen $(4 \mu \mathrm{g} / \mathrm{ml})$ in an aggregometer for $5 \mathrm{~min}$. The supernatant of this mixture was then counted after centrifugation. The difference in counts before and after aggregation, expressed as a percentage of the uptake-that is, the difference in counts before and after incubationwas then used as a measure of release.

\section{PLATELET NUCLEOTIDE MEASUREMENT}

Platelet adenosine triphosphate (ATP) and ADP were assayed by high performance liquid chromatography following extraction with perchloric acid. A platelet rich plasma count of $300 \times$ $10^{9} / 1$ was used where possible; at lower counts a proportionate reduction in materials was made. Edetic acid $(1.2 \mathrm{ml})$ was added to $3 \mathrm{ml}$ of platelet rich plasma and centrifuged at $3000 \mathrm{rpm}$ at $4^{\circ} \mathrm{C}$ for $20 \mathrm{~min}$ and the supernatant discarded. The platelet button was resuspended in the base of the tube and stored at $-80^{\circ} \mathrm{C}$ before assay (within two weeks of sampling). Then $0.6 \mathrm{ml}$ of perchloric acid (0.3M) was added and the solution respun. ATP and ADP were assayed in the supernatant by reverse phase high performance liquid chromatography using a Waters Radial Compression Rad Pak (C18) with $0 \cdot 15 \mathrm{M}$ ammonium dihydrogen orthophosphate $(\mathrm{pH}$ $5 \cdot 45)$ as buffer.

\section{PLATELET MEMBRANE GLYCOPROTEINS}

Platelet membrane glycoproteins were measured in blood anticoagulated with ACD $(2.5 \%$ wt/vol sodium citrate, $2.0 \% \mathrm{wt} / \mathrm{vol}$ dextrose, $1.5 \% \mathrm{wt} / \mathrm{vol}$ citric acid), diluted $1 / 7$ with blood. Platelet rich plasma was centrifuged at $3000 \mathrm{~g}$ for $15 \mathrm{~min}$ and the platelet pellet was resuspended in a washing buffer $(10 \mathrm{mM}$ Tris, $150 \mathrm{mM} \mathrm{NaCl}, 1 \mathrm{mM}$ edetic acid $5 \mathrm{mM}$ glucose, $\mathrm{pH} \mathrm{7.4)}$ and washed twice. The final platelet button was resuspended at a concentration of $4 \times 10^{9}$ platelets per millilitre, freeze dried, and stored at $-20^{\circ} \mathrm{C}$ until analysed. The preparation was reconstituted in distilled water and diluted in sample buffer (0.0625 M Tris, $2.3 \% \mathrm{wt} /$ vol sodium dodecylsulphate, and $10 \% \mathrm{vol} / \mathrm{vol}$ glycerol; $\mathrm{pH} 6 \cdot 8)$ with or without $\beta$-mercaptoethanol ( $5 \% \mathrm{vol} / \mathrm{vol})$ and heated at $100^{\circ} \mathrm{C}$ for $5 \mathrm{~min}$. Electrophoresis was carried out immediately at $30 \mathrm{~mA}$ on slab gels consisting of $7.5 \%$ separating gel and a $3 \%$ stacking gel with $0.2 \%$ cross linkage using the Laemmli buffer system until a bromophenol blue mark had reached the bottom of the gel. ${ }^{4}$ Samples consisting of $1.5 \times 10^{8} / 1$ platelets were applied with a constant volume of fetuin (Sigma type III). After electrophoresis peptides were fixed in $12.5 \% \mathrm{wt} / \mathrm{vol}$ trichloroacetic acid for $15 \mathrm{~min}$. The glycoproteins were oxidised with periodic acid, washed extensively, and stained with Schiff's reagent (Sigma). Quantitation was performed using a scanning densitometer at $550 \mathrm{~nm}$ and areas of individual membrane peaks were determined from 'both the unreduced and reduced sample scans.

\section{Results}

The clinical details and template bleeding times for the 13 patients are given in Table 1 . Of the six patients with platelet counts greater than $100 \times$ $10^{9} / 1$ and who had bleeding times performed, two had prolonged times and two had times at the upper limit of normal (normal range $3.63 \pm 2.42 \mathrm{~min}$ ).

In all investigations no difference was found between measurements performed on platelet rich

Table 1 Patient details and template bleeding time

\begin{tabular}{|c|c|c|c|c|c|c|}
\hline Patient no & $\begin{array}{l}\text { Age } \\
\text { (yr) }\end{array}$ & $\operatorname{Sex}$ & $\begin{array}{l}\text { White cell count } \\
\text { (blast) }\left(\times 10^{4} / l\right)\end{array}$ & $\begin{array}{l}\text { Platelet count } \\
\left(\times 10^{9} / l\right)\end{array}$ & $F A B$ type $e^{2}$ & $\begin{array}{l}\text { Template bleeding } \\
\text { time (min) }\end{array}$ \\
\hline $\begin{array}{r}1 \\
2 \\
3 \\
4 \\
5 \\
6 \\
7 \\
8 \\
9 \\
10 \\
11 \\
12 \\
13\end{array}$ & $\begin{array}{l}15 \\
77 \\
58 \\
15 \\
56 \\
56 \\
39 \\
30 \\
58 \\
58 \\
52 \\
47 \\
63\end{array}$ & $\begin{array}{l}\mathbf{M} \\
\mathbf{M} \\
\mathbf{F} \\
\mathbf{F} \\
\mathbf{M} \\
\mathbf{M} \\
\mathbf{F} \\
\mathbf{F} \\
\mathbf{F} \\
\mathbf{F} \\
\mathbf{F} \\
\mathbf{F} \\
\mathbf{M}\end{array}$ & $\begin{array}{l}54(38) \\
244(219) \\
0.7(0) \\
6 \\
0 \cdot 9(0) \\
3 \\
1 \cdot 9(0) \\
16 \quad(1 \cdot 6) \\
38 \quad(33) \\
52 \quad(36) \\
1 \cdot 2(0) \\
2 \cdot 1(0) \\
1.7(0)\end{array}$ & $\begin{array}{l}367 \\
103 \\
220 \\
135 \\
120 \\
124 \\
80 \\
74 \\
75 \\
80 \\
105 \\
209 \\
183\end{array}$ & $\begin{array}{l}\text { M4 } \\
\text { M4 } \\
\text { M1 } \\
\text { M4 } \\
\text { M2 } \\
\text { M5 } \\
\text { M4 } \\
\text { M4 } \\
\text { M5 } \\
\text { M4 } \\
\text { M1 } \\
\text { M3† } \\
\text { M6 }\end{array}$ & $\begin{array}{l}7 \\
3 \cdot 25 \\
\text { ND } \\
\text { ND } \\
\text { ND } \\
5 \cdot 75 \\
4 \\
12 \\
6 \\
8 \cdot 5 \\
6 \\
8 \cdot 25 \\
5\end{array}$ \\
\hline
\end{tabular}

*Normal range $=3.63 \pm 2.42 \mathrm{~min}$.

$\dagger$ Patient with promyelocytic leukaemia.

$\mathrm{ND}=$ not done 
Table 2 Platelet aggregation, ${ }^{14} \mathrm{C}$ 5-hydroxytryptamine uptake and release, and thromboxane $B_{2}$ production

\begin{tabular}{|c|c|c|}
\hline & Patients & Control(8) \\
\hline \multicolumn{3}{|l|}{$\begin{array}{l}\text { Platelet aggregation (\%) } \\
(n=13)\end{array}$} \\
\hline $\begin{array}{l}1 \mu \mathrm{M} \text { ADP } \\
5 \mu \mathrm{M} \text { ADP } \\
2 \mu \mathrm{g} / \mathrm{ml} \text { collagen } \\
4 \mu \mathrm{g} / \mathrm{ml} \text { collagen }\end{array}$ & $\begin{array}{l}27 \cdot 8(6 \cdot 83) \\
42 \cdot 5(6 \cdot 29) \\
21 \cdot 6(8 \cdot 63) \\
39 \cdot 9(7 \cdot 28)\end{array}$ & $\begin{array}{l}29.9(5.59) \\
81.6(5.86)^{*} \\
76.25(5.71)^{*} \\
89.25(3.07)^{*}\end{array}$ \\
\hline \multicolumn{3}{|c|}{$\begin{array}{l}{ }^{14} \mathrm{C}-5-\text { hydroxytryptamine } \\
(\mathrm{n}=9)\end{array}$} \\
\hline $\begin{array}{l}\text { Uptake } \\
\text { Release }\end{array}$ & $\begin{array}{l}46 \cdot 3(4 \cdot 53) \\
4 \cdot 66(2 \cdot 06)\end{array}$ & $\begin{array}{ll}80 & (5 \cdot 22)^{*} \\
37.8 & (3 \cdot 85)^{*}\end{array}$ \\
\hline $\begin{array}{l}\text { Thromboxane } \mathrm{B}_{2} \text { produ } \\
\text { ( } \mathrm{n}=10) \\
\text { (pmol } 10^{\prime} \text { platelets) }\end{array}$ & $\begin{array}{l}\text { luction } \\
2.9 \quad(1.9)\end{array}$ & $16.59(2.06)^{*}$ \\
\hline
\end{tabular}

Values given as mean (SE).

The figure for thromboxane $B_{2}$ production is a median.

"p $<0.01$ (Wilcoxon's rank sum test).

plasma from eight normal subjects tested at platelet counts of 100 and $300 \times 10^{\%} / \mathrm{l}$. The results obtained did not differ from previously established laboratory normal ranges.

In samples from the patients the maximal platelet aggregation response to $1 \mu \mathrm{M}$ ADP was similar to that found in normal subjects (Table 2). At a final concentration of $5 \mu \mathrm{M}$ ADP the maximal platelet aggregation was significantly less than normal platelets. Biphasic aggregation was present in all normal subjects and in 11/13 patients' samples. Significant subnormal aggregation responses were also seen when patients' platelets were stimulated with collagen at concentrations of $2 \mu \mathrm{g} / \mathrm{ml}$ and 4 $\mu \mathrm{g} / \mathrm{ml}$.

The uptake and release of ${ }^{14} \mathrm{C}$-5-hydroxytryptamine by platelets, measured in samples from nine patients, was considerably reduced compared with results obtained with platelets from normal subjects. Five patients failed to release detectable ${ }^{14} \mathrm{C}-5$ hydroxytryptamine in response to collagen. The mean platelet ATP and ADP contents (measured in platelets from 10 patients) were reduced when compared with the results from a large group of normal people used to establish a normal range (Table 3 ). Only the reduction in ADP was statistically significant. The ATP to ADP ratio was significantly raised above the normal mean, but only one value was more than two standard deviations from the

Table 3 Platelet nucleotide estimations (nmol/10 platelets)

\begin{tabular}{lll}
\hline Platelet nucleotide & $\begin{array}{l}\text { Patients } \\
(n=10)\end{array}$ & $\begin{array}{l}\text { Normal subjects } \\
(n=51)\end{array}$ \\
\hline ATP & $5 \cdot 29(0.47)$ & $6.25(0.15)$ \\
ADP & $2.95(0.3)$ & $4.01(0.12)^{*}$ \\
ATP:ADP & $1.82(0.12)$ & $1.61(0.08)^{*}$ \\
\hline
\end{tabular}

"p $<0.05$ (Wilcoxon's rank sum test).

Values given as mean \pm ( $1 \mathrm{SE})$. mean of 51 normal subjects. This patient had a ratio of 2.4 and was the only patient with acute promyelocytic leukaemia studied.

Thromboxane $\mathrm{B}_{2}$ production in response to collagen stimulation was considerably reduced in $9 / 10$ patients studied. The median value is given in Table 2 to avoid the distortion of the mean created by the one high normal value. The platelet membrane glycoprotein profile was studied in seven patients and did not differ significantly from normal in six. One patient (no 4) had an apparent striking increase in staining in the region of glycoprotein IV.

\section{Discussion}

Study of the acquired platelet defect in acute myeloblastic leukaemia is complicated by the difficulty in obtaining sufficient platelets for study. Although manual thrombopheresis has been used ${ }^{5}$ with subsequent platelet concentration before study, an alternative is to select those patients presenting with sufficiently high platelet counts to prepare satisfactory platelet rich plasma. This latter approach restricts the number of patients available for study, particularly when those with systemic infection and those who have taken platelet inhibitory drugs are excluded. Furthermore, the selection is biased to those with the most effective thrombopoiesis and longer platelet survival. The degree of in vitro manipulation, however, is reduced to that generally required for the performance of platelet function tests. It is for this reason that we selected those patients with the highest platelet counts.

While we have confirmed that defects in platelet aggregation are detectable by platelet aggregometry two points should be noted. Aggregations performed at a low concentration of ADP $(1 \mu \mathrm{M})$ were not obviously impaired. Aggregation performed at a higher concentration of $5 \mu \mathrm{M}$, although significantly reduced, remained biphasic in 11 of 13 patients studied. This contrasts with the results of Cowan and Haut,' who could not detect any second wave aggregation when platelets from patients with acute myeloblastic leukaemia were aggregated with ADP. A defect in aggregation was apparent at both concentrations of collagen.

The platelets from our patients had considerably impaired uptake and collagen induced release of ${ }^{14} \mathrm{C}$-5-hydroxytryptamine when compared with those of normal volunteers. A similar defect of release was seen by Cowan et al, ${ }^{5}$ who stimulated platelets labelled in vitro with ${ }^{14} \mathrm{C}$-adenine with thrombin. In this latter study, however, the uptake of labelled nucleotide was normal.

We have failed to show a convincing storage pool defect in the platelets of patients with acute myelo- 
blastic leukaemia. There was a significant reduction in platelet ADP and a smaller, but not significant, reduction in platelet ATP. Although the ATP to ADP ratio was slightly raised at $1 \cdot 8$, all but one patient had a ratio within two standard deviations of the mean derived from 51 normal subjects. The other patient had a ratio of 2.4 and had promyelocytic leukaemia. In contrast, Cowan et $a^{5}$ found a mean ATP to ADP ratio of 3.5 in nine patients with leukaemia. The difference between this study and ours may be partially explained by the inclusion in the study of Cowan et al of three patients with chronic granulocytic leukaemia in blast cell crisis and two patients with hairy cell leukaemia. In both of these conditions a storage pool defect, as indicated by a high ATP to ADP ratio, has been shown. ${ }^{67}$

Thromboxane $\mathrm{B}_{2}$ is the stable breakdown product of thromboxane $A_{2}$, a chemical mediator of the release reaction. On stimulation of the platelet, arachidonic acid is released from the membrane and converted to thromboxane $\mathrm{A}_{2}$ by the enzymes cyclo-oxygenase and thromboxane synthetase. When the production of thromboxane $B_{2}$ was measured after stimulation of the platelets with collagen it was found to be considerably reduced in nine of 10 patients studied. This is a new finding and may at least partially explain the defective release reaction seen in these patients' platelets. A number of possible explanations may account for this finding. These include a receptor defect, alteration of phospholipase activity, reduced cyclo-oxygenase activity or thromboxane synthetase activity, or a reduction in the arachidonic acid content of the membrane phospholipids. Further investigation, including platelet responses and thromboxane production on stimulation with arachidonic acid, would be necessary to define this further. We did not find any consistent changes in the platelet membrane glycoproteins, although one patient had an increased glycoprotein IV.

The mechanism underlying the disturbance of platelet function is difficult to define. Platelet production is normal or increased in most patients with acute myeloblastic leukaemia. ${ }^{8}$ Thrombopoiesis is probably defective due to involvement in the neoplastic process or disturbed marrow function. The production of functionally abnormal platelets might lead to the reduced life span and thrombocytopenia. ${ }^{8}$ Also modification of the platelets might occur in the circulation due to activation by malignant cells. Appreciable intravascular release is unlikely, however, as we have not shown a storage pool defect and $\beta$-thromboglobulin concentrations are low in this condition."

The results of this study identify a previously unreported reduction in thromboxane synthesis in acute myeloid leukaemia. They suggest that the abnormality differs from that present in chronic myeloproliferative disorders, in which a storage pool defect is often present and thromboxane synthesis may be normal or increased. ${ }^{70}$ The presence of normal or only moderately prolonged bleeding times in these patients confirms previous observations " ${ }^{11}$ and suggests that the abnormalities identified would at worst be associated with a mild bleeding tendency. Defective platelet function is probably a consequence of abnormal thrombopoiesis and it is of interest that megakaryocyte size (possibly an index of effective thrombopoiesis) is important in determining the response of children with this condition to treatment. ${ }^{12}$

We thank Dr $M$ Greaves for helpful advice, CA Jackson for thromboxane $B_{2}$ assay, and Mrs $M$ Raymond for typing the manuscript.

\section{References}

' Cowan DH. Haut MJ. Platelet function in acute leukaemia. J Clin Lab Med 1972:79:893-905.

${ }^{2}$ Bennett JM, Catovsky D, Daniel MT, et al. The FrenchAmerican-British (FAB) Cooperative group proposals for the classification of Acute Leukaemia. Br J Haematol 1976;33:451-8.

${ }^{3}$ Jackson CA, Greaves M, Paterson AD, Brown CB, Preston FE. Relationship between platelet aggregation, thromboxane synthesis and albumen concentration in the nephrotic syndrome. Br J Haematol 1982; 52:69-77.

${ }^{4}$ Laemmli UK. Cleavage of structural proteins during the assembly of the head of Bacteriophage T4. Nature 1970;227:680.

${ }^{5}$ Cowan DH, Graham RC, Baunach D. The platelet defect in acute leukaemia. J Clin Invest 1975;56:188-200.

- Rosove MH, Naiem F, Harwig S, Zighelboim J. Severe platelet dysfunction in hairy cell leukaemia with improvement after splenectomy. Blood 1980;55:903-6.

7 Gerrard JM, Stoddard SF, Shapiro RS, et al. Platelet storage pool deficiency and prostaglandin synthesis in chronic granulocytic leukaemia. Br J Haematol 1978;40:597-607.

${ }^{8}$ Cowan DH. Thrombokinetics in acute non lymphocytic leukaemia J Clin Lab Med 1973;82:911-23.

${ }^{\bullet}$ Kutti J, Zaroulis CG, Kulpa J, Reich L, Clarkson BD, Good RA. Plasma B-thromboglobulin values in thrombocytopenic patients with acute leukaemia. Am J Haematol 1980;8:339 45.

${ }^{10}$ Pareti FI, Gugliotta L, Manucci L, Fuarini A, Manucci PM. Biochemical and metabolic aspects of platelet dysfunction in chronic myeloproliferative disorders. Thromb Haemostas (Stuttgart) 1982;47:84-9.

"Van Der Weyden MB, Clancy RL, Howard MA, Firkin BG. Qualitative platelet defects with reduced life-span in acute leukaemia. Aust NZ J Med 1972;4:339-45.

12 Jackson CW, Dahl GV. Relationship of megakaryocyte size at diagnosis to chemotherapeutic response in children with acute non-lymphocytic leukaemia. Blood 1983;61:867-70.

Requests for reprints to: Dr BE Woodcock, Department of Haematology, Royal Hallamshire Hospital, Glossop Road, Sheffield S10 2JF, England. 